\title{
Numerical Investigation on Jet Impingement Behaviors Affected by a Vertically Rotating Disk Suspended Close to the Surface
}

\author{
Liu Bo, ${ }^{1}$ Zhang Jing-zhou, ${ }^{2,3}$ and Tan Xiao-ming ${ }^{1}$ \\ ${ }^{1}$ College of Energy and Power Engineering, Nanjing University of Aeronautics and Astronautics, Nanjing 210016, China \\ ${ }^{2}$ Jiangsu Province Key Laboratory of Aerospace Power System, Nanjing University of Aeronautics and Astronautics, \\ Nanjing 210016, China \\ ${ }^{3}$ Collaborative Innovation Center of Advanced Aero-Engine, Beijing 100191, China
}

Correspondence should be addressed to Zhang Jing-zhou; zhangjz@nuaa.edu.cn

Received 23 May 2014; Accepted 3 July 2014; Published 12 August 2014

Academic Editor: Gongnan Xie

Copyright (C) 2014 Liu Bo et al. This is an open access article distributed under the Creative Commons Attribution License, which permits unrestricted use, distribution, and reproduction in any medium, provided the original work is properly cited.

A simplified physical model is built up to study the swirl flow effect induced by a rotating disk on the jet impingement behaviors, which is adopted to simulate the grinding process. To solve the definition problem of the interface between a rotating disk and a stationary plate in the computational simulation, a tiny gap is set between the rotating disk and the stationary plate. The results show that the rotating disk suspended above the surface adds more complexity to the flow field of jet impingement on a stationary plate. The swirling flow around the rotating disk obstructs the impinging jet flow to penetrate into the interfacial contact zone and forces the wall jet across the rotating disk to flow along transverse directions. For the given jet impinging velocity and nozzle orientation, as the disk rotational speed increases, the effect of the rotating disk on the impinging jet flow behaves more significantly. The impinging jet with small inject velocity is difficult to penetrate through the interfacial contact zone to follow by the disk swirl flows. For smaller jet impinging distance or larger oblique angle, the flow recirculation away from the interfacial contact zone becomes stronger.

\section{Introduction}

Grinding is a widely employed machining process used to achieve good geometrical form, dimensional accuracy, surface finish, and surface integrity. The grinding process requires higher energy expenditure per unit volume of material removed. Virtually all of this energy is dissipated as the heat at the grinding zone where the wheel interacts with the workpiece. It is often considered that in most cases a larger part of the heat will end up in the workpiece. As a consequence, a high temperature may be experienced by the grinding surface, which can cause various types of thermal damage [1]. The traditional method for the cooling of the grinding zone is the use of liquid coolants, usually an oilin-water emulsion, or neat oil. Liquid coolants provide bulk cooling of the workpiece and removal of swarf, but unless special pumps are used, their low speed and kinetic energy will not allow them to penetrate the fast moving boundary layer forming around a fast-rotating grinding wheel, so they never reach the grinding zone. In addition, liquid coolants, based on water, have relatively low boiling points and with the onset of film boiling their heat transfer capabilities diminish dramatically [2]. Furthermore, strong arguments against their continued use are the expensive cost and pollution in both the exploitation and disposal phases. Substantially, environmental and resource problems have urged the search for alternative cooling agents without or with less chemical additives becoming an active study recently $[3,4]$.

Jet impingement is an excellent scheme for heat transfer enhancement. It provides significantly high local heat transfer coefficient on the impinging jet stagnation zone for the main reason is that the jet impingement forms a very thin stagnant boundary layer. Due to its simple design and low cost, jet impingement has been employed in a wide variety of practical applications that aim to achieve intense heating, cooling, or drying rates [5-7]. Mist/air jet impingement directed at 
grinding zone is regarded as one of the promising cooling solutions to satisfy the following conditions: to be effective, cheap, and environment friendly. Babic et al. [8] described some experiments on the grinding process with mist/air jet cooling by injecting a small amount of water into the air flow. Evaporation of the miniaturized droplets of water impinging upon a superheated surface through the phase change process considerably added to the overall heat removal, and this made the discussed type of cooling much more efficient as compared with that caused by the air flow under otherwise identical conditions.

Numerous investigations on the heat transfer enhancement of single-phase and two-phase impinging jets have been conducted and are available in the literature [9-14]. These investigations have shown that the heat transfer produced by an impinging jet depends mainly on a number of parameters, including the Reynolds number of the jet, the jet-to-target spacing, mist-to-air ratio, the presence of a confining wall, and the nozzle geometry. With regard to the application of jet impingement in the cooling of grinding process, the inherent nature of the jet impingement heat transfer on grinding workpiece differs undoubtedly from the cases of free jet impingement. Owing to the spinning grinding wheel, the interaction between the swirl flow entrainment induced by the spinning disk and jet impingement provides the conjugate effect in the vicinity of a rotating grinding wheel, making the convective heat transfer on grinding workpiece surface more complex. Some investigations have been done for the heat transfer enhancement over rotating disk by jet impingement. Saniei and Yan [15] presented local heat transfer measurements for a rotating disk cooled with an impinging air jet. Several important factors such as rotational Reynolds number, jet Reynolds number, jet-to-disk spacing, and the location of the jet center relative to the disk center were examined. Minagawa and Obi [16] studied turbulent fluid flow structure of an impinging jet on a rotating disk. They concluded that rotation has a significant effect on skew of mean flow and centrifugal force. Abdel-Fattah [17] investigated the fluid flow characteristics numerically by using $k-\varepsilon$ RNG model and compared his results with those of Minagawa and Obi [16]. Temperature filed and convective heat transfer coefficient on a rotating disk subjected to a jet impingement were evaluated experimentally by Astarita and Cardone [18]. They considered the interaction of turbulent jet and boundary layer on disk due to rotation. O'Donovan et al. [19] made an experiment on jet heat transfer in the vicinity of a rotating grinding wheel. In their experiment, a grinding wheel was suspended about $0.5 \mathrm{~mm}$ above the surface and was driven with an AC motor. Contact was not made between the grinding wheel and the surface to ensure that the sensors were not damaged by the rotating wheel. It had been shown that a boundary layer that develops around the rotating grinding wheel had the effect of displacing a peak in the distribution of the local heat transfer coefficient from the notional arc of cut. To effectively cool the grinding zone, therefore, it was necessary to penetrate this boundary layer and this could only be achieved when the jet velocity was substantially greater than the tangential velocity of the wheel. Recently, Zhang et al. [20] carried out an investigation to illustrate some of the flow and heat transfer characteristics that occurred when a single-air jet or mist/air jet impinged on a flat plate with a rotating disk mounted above the surface, representative of the workpiece in a grinding process. Their results showed that the coupled action of swirl air entrainment and jet impingement was benefit somewhat for overall convective heat transfer enhancement in relative to the case where the disk is stationary. When the jet impinging direction was consistent with the rotational direction of rotating disk, convective heat transfer enhancement was achieved near grinding zone, especially at higher rotating speed. Furthermore, the increasing of water droplet in mist/air jet impingement showed significant enhancement of the cooling effect.

To our knowledge, previous studies paid little attention to the interaction between an impinging jet and swirl flow induced by rotating disk, as well as the effects of swirl flow on the jet impingement behaviors. In current study, numerical investigation was conducted to provide detailed insight into the effect of the swirl flow induced by a rotating disk on the jet impingement behaviors. Several factors, such as disk rotational speed, impinging jet velocity, and nozzle orientation, were taken into consideration.

\section{Description of Physical Model}

The geometric parameters of a grinding process are depicted in Figure 1. The grinding wheel is shown to rotate in a clockwise direction with a rotational speed $\Omega$. The workpiece is fed with a velocity $V_{w}$ in the direction of the wheel. The depth of cut, $a$, shown to be exaggerated in the diagram, is typically about $5 \mu \mathrm{m}$ during conventional grinding. The workpiece exerts a tangential force, $F_{t}$, on the grinding wheel. In this configuration, the jet flows in the direction of the workpiece with velocity $V_{j}$. The power generated during the grinding process is dissipated as heat in the grinding zone, where this heat flux is approximately defined by O'Donovan et al. [19]:

$$
q=\frac{F_{t} V_{g}}{b \sqrt{a D}}
$$

where $V_{g}$ is the tangential velocity of the grinding wheel and $b$ and $D$ are the width and diameter of the grinding wheel, respectively.

Considering the difficulties in the flow and heat transfer simulation of a real grinding process, a simplified physical model is built up to study the behaviors of jet impingement on a plate with a rotating disk suspended above the surface, as seen in Figure 2. Three main approximations are made in the present physical model. Firstly, to solve the definition problem of the interface between a rotating disk and a stationary plate, a tiny gap of $0.02 \mathrm{~mm}$ is set between the rotating disk and the stationary plate [20]. Although this simplified case contrasts with the actual grinding process where the grinding wheel is in contact with the workpiece, it becomes feasible for inquiring the conjugate effect of swirl flow induced by the rotating disk and impinging jet in the current study. This approximation is not considered to be significant for the conventional grinding process where 


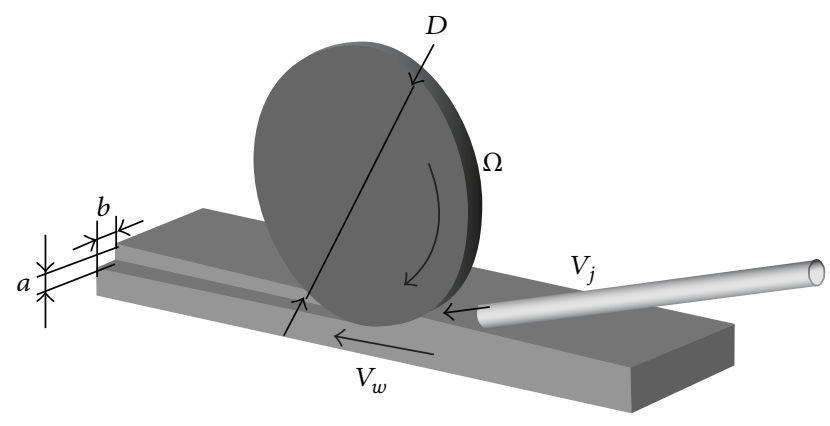

FIGURE 1: Schematic diagram of grinding process [19].

the depth of cut is very little according to the investigation by Ebbrell et al. [21] who investigated the effect of such a gap on the pressure distribution along the grinding plane and the back flow resulting from the grinding wheel boundary layer. They pointed out that the smallest gap $\delta$ of $0.005 \mathrm{~mm}$ approximated the grinding process quite accurately as the contact area between the grinding wheel and the workpiece was typically only a small percentage of the total grinding zone area. The consequence of the relatively large gap was a reduction in the magnitude of the back flow by allowing some flow under the grinding wheel surface. The second approximation is that the plate representing the workpiece is assumed to be stationary. In a grinding process, the workpiece typically traverses under the grinding wheel with a velocity of about $0.2 \mathrm{~m} / \mathrm{s}$. This velocity is extremely small relative to both the impinging jet velocity and the grinding wheel tangential velocity, and, therefore, neglecting it will not have a significant influence on the results.

In the present study, the diameter and width of the rotating disk are fixed at $D=200 \mathrm{~mm}$ and $b=50 \mathrm{~mm}$, respectively. The central plane of disk is located at the symmetry plane in $z$-direction. Two coordinate systems are selected as stationary coordinate system with original point located at the center of plate and rotational coordinate system with original point located at the center of disk. By varying the rotational speed of disk $(\Omega)$, impinging jet velocity $\left(V_{j}\right)$, and jet nozzle orientation (impinging distance $H$ and oblique angle $\alpha$ ), the behaviors of jet impingement on a heated plate with a rotating disk suspended above the surface are investigated numerically.

\section{Computation Scheme}

3.1. Brief Description of Computational Method. A computational region is selected according to Figure 2. The flat plate is $500 \mathrm{~mm}$ in length and $200 \mathrm{~mm}$ in width. The diameter of jet nozzle is $10 \mathrm{~mm}$. The computational domain is surrounded with enough ambient space.

A numerical computation is carried out by using FluentCFD software. To trace the flow of impinging jet, the impinging fluid is set as $\mathrm{CO}_{2}$ and the surrounding fluid is set as $\mathrm{N}_{2}$. In the computation focusing on the flow fields without taking heat transfer into consideration, the governing equations include conservation of mass and momentum, as well as species transport equation. Those equations are listed as follows:

$$
\begin{gathered}
\nabla \cdot(\rho \vec{v})=0, \\
\rho(\vec{v} \cdot \nabla) \vec{v}=-\nabla p+\nabla \cdot \bar{\tau}, \\
\nabla \cdot\left(\rho \vec{v} Y_{j}\right)=-\nabla \cdot \vec{J}_{j},
\end{gathered}
$$

where $\rho$ is density of gas, $\vec{v}$ is velocity vector, $p$ is static pressure, $\bar{\tau}$ is stress tensor, and $\vec{J}_{j}$ and $Y_{j}$ represent diffusion flux and local mass fraction for species $j$. The MaxwellStefan model is adopted to calculate the diffusive flux for a multicomponent diffusion system with only considering the species of $\mathrm{CO}_{2}$ and $\mathrm{N}_{2}$. The properties of the gas mixture are treated by the assumption of an ideal gas mixture.

The computation domain is composed of rotating disk, stationary plate, jet nozzle, and surrounding fluid. The boundary conditions for the flow field simulation are specified as follows.

The impinging jet outlet is defined as the velocity outlet. The mean jet velocity at the outlet $\left(V_{j}\right)$ is determined between $10 \mathrm{~m} / \mathrm{s}$ and $50 \mathrm{~m} / \mathrm{s}$. A turbulence intensity of $0.5 \%$ and a turbulence length scale of $3 \%$ of the nozzle diameter are used. Local mass fraction of $\mathrm{CO}_{2}$ is set as 1 and local mass fraction of $\mathrm{N}_{2}$ is set as 0 .

The surfaces of disk are modeled as "solid-fluid" coupling boundaries. A rotational angular speed between $0 \mathrm{rpm}$ and $4000 \mathrm{rpm}$ is applied to the solid disk.

No-slip wall boundary condition is imposed for the stationary plate surface.

Two fictitious boundaries of ambient fluid domain at $z$-direction are set as zero gradients for all the variables. The other boundaries of ambient fluid domain are set as undisturbed boundaries with ambient pressure of $101325 \mathrm{~Pa}$. The local mass fraction of $\mathrm{N}_{2}$ is set as 1 and local mass fraction of $\mathrm{CO}_{2}$ is set as 0 .

The computation domain grids are divided using the GAMBIT software. Meshes are refined in some critical areas to ensure coverage for satisfactory resolution, especially near the no-slip walls where velocity gradients are expected to be high. Viscous clustering is employed at all solid walls with a $y^{+}$value less than 2.5 at all locations. Based on the mesh independence test, approximately 300,000 computational grids are involved in the whole computational domain. RNG $k-\varepsilon$ turbulence model provided in the FluentCFD software is used to model turbulence, and the nearwall region is modeled using an enhanced wall function. Although Zuckerman and Lior [22] pointed out that the shear stress transport (SST) turbulence model was better for the prediction of impingement heat transfer, the flow in the near-wall regime simulated using a low-Reynolds number approach needed very fine mesh length scales next to the wall. Considering that the present computation aims mainly at the simulation of impinging jet flow fields, as well as the successful applications of RNG $k-\varepsilon$ turbulent model in complex three-dimensional turbulent flows, such as mixing flow, impinging jet flow, and rotating cavity flow [23-26], thus, in terms of accuracy and computational effort, RNG $k-\varepsilon$ turbulence model is used in the present study. 


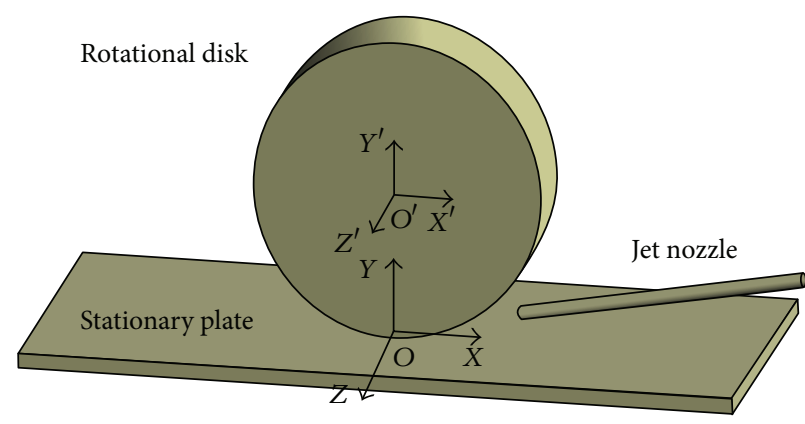

(a) Fictitious grinding

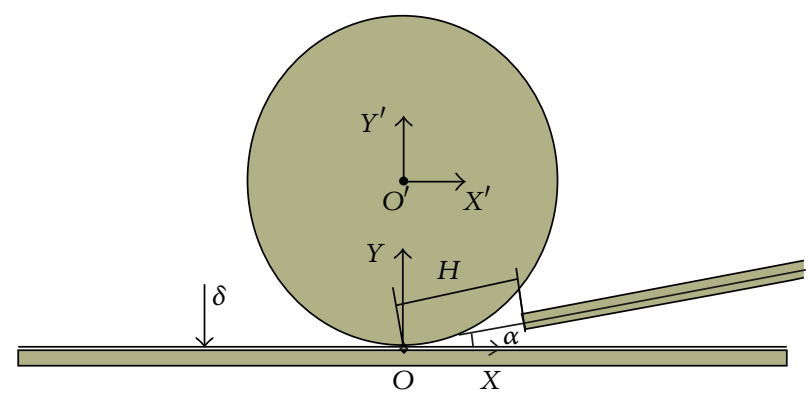

(b) $x \mathrm{o} y$ section

Figure 2: Schematic of physical model.

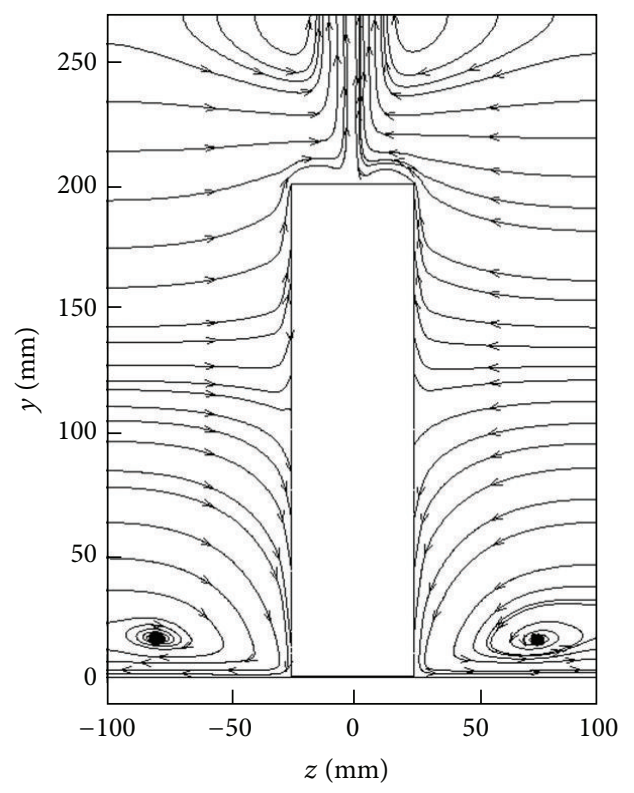

(a) $y \mathrm{o} z$ section

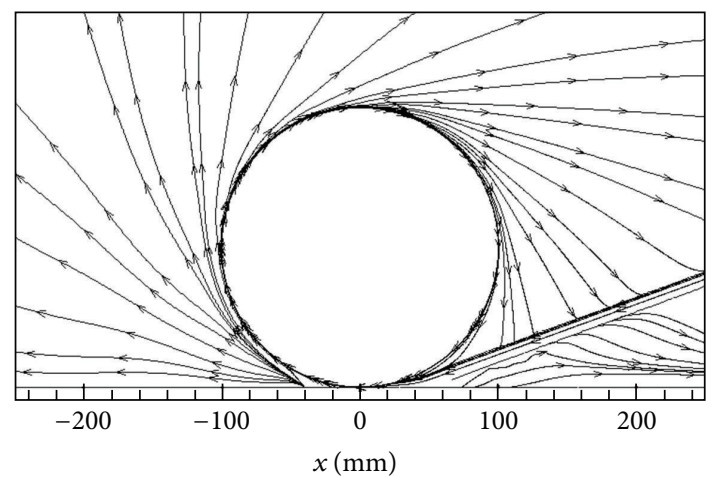

(b) $x \mathrm{o} y$ section

FIgURE 3: Computed streamline pattern at central planes $\left(\Omega=2000 \mathrm{rpm}, V_{j}=30 \mathrm{~m} / \mathrm{s}, H=80 \mathrm{~mm}\right.$, and $\left.\alpha=10^{\circ}\right)$.

The diffusive fluxes are approximated using secondorder central differences. Convergence is achieved when the reduction in all residuals of five orders of magnitude has been met. More details on these solvers could be found in the Fluent Software User's Guide.

\section{Results and Analysis}

Figure 3 presents the computed streamline patterns at central planes of the computational domain, which is displayed for the rotational speed of $2000 \mathrm{rpm}$ and jet velocity of $30 \mathrm{~m} / \mathrm{s}$. Specifically, the jet nozzle outlet is fixed at $H=80 \mathrm{~mm}$ with oblique angle of $10^{\circ}$. It is obviously viewed that a rotating disk entrains fluid from the surroundings and induces a spiral fluid flow over the rotating disk. It is illustrated that the spiral fluid flow induced only by a free rotating disk is an extremely complicated three-dimensional motion. The predominant flow direction is tangential relative to the coordinate system located at the center of disk, but radial velocities across the disk are generated by centrifugal forces and this induces entrained flow toward the disk. Once the rotating disk is suspended above a plate surface, the confined bound of the plate affects the spiral fluid flow seriously. The swirl flow induced by the rotating disk rim comes into close proximity to the plate surface in the same direction as the rotating disk, coupled with the impinging jet flow in the front wedge between the rotating disk and the stationary plate surface. As the mixing flow reaches the minimum gap between the rotating disk and the stationary plate, some of the flow stagnates and then flows backwards away from the stagnation point. This is understandable as the relatively small gap between the disk and the surface allows a little of the jet to pass under the disk. Simultaneously, the radial flow of entrained fluid pumped toward the disk centre forms wall jet over the stationary plate surface in the traverse direction 


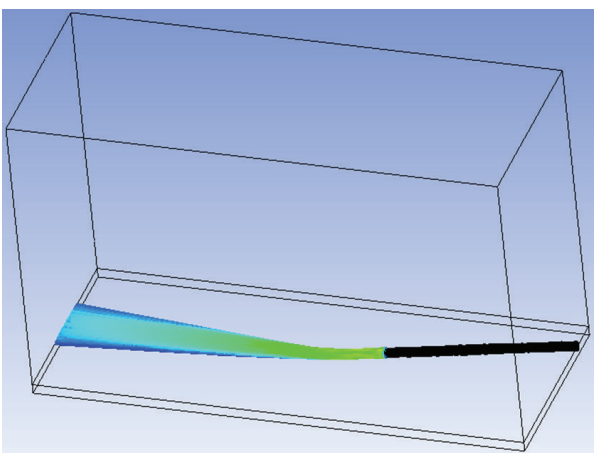

(a) Free oblique jet, $V_{j}=30 \mathrm{~m} / \mathrm{s}$

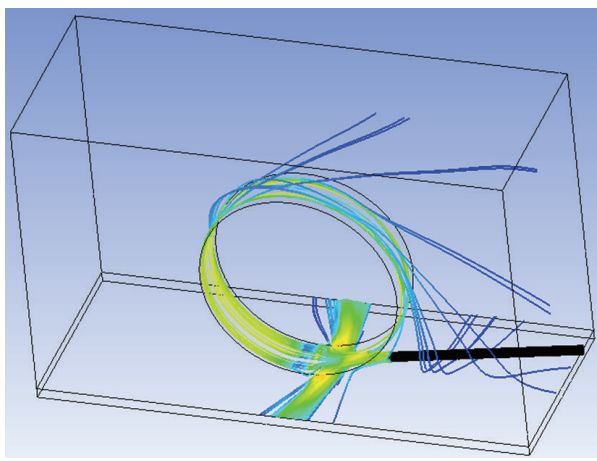

(c) $\Omega=2000 \mathrm{rpm}, V_{j}=30 \mathrm{~m} / \mathrm{s}$
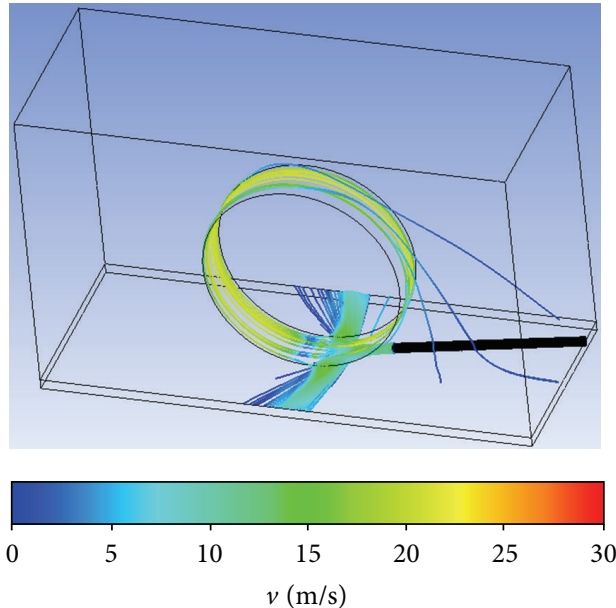

(e) $\Omega=2000 \mathrm{rpm}, V_{j}=20 \mathrm{~m} / \mathrm{s}$

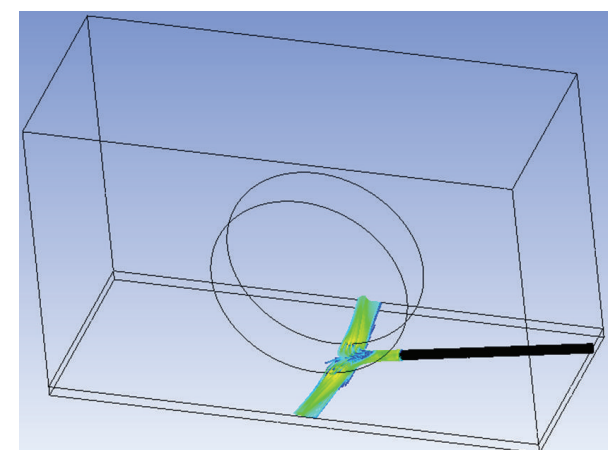

(b) $\Omega=0 \mathrm{rpm}, V_{j}=30 \mathrm{~m} / \mathrm{s}$

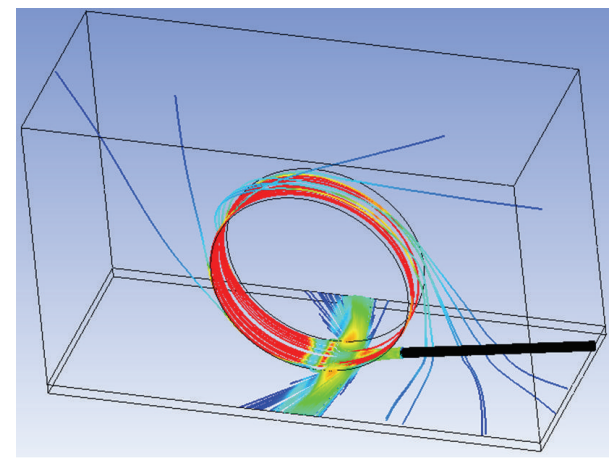

(d) $\Omega=4000 \mathrm{rpm}, V_{j}=30 \mathrm{~m} / \mathrm{s}$
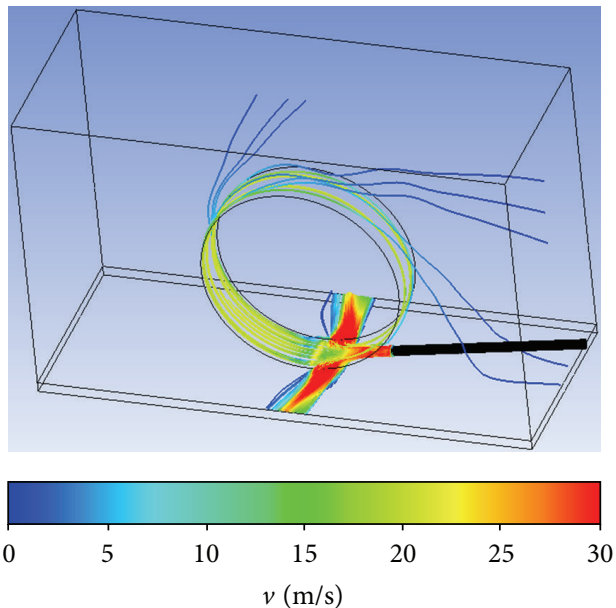

(f) $\Omega=2000 \mathrm{rpm}, V_{j}=50 \mathrm{~m} / \mathrm{s}$

Figure 4: Impinging jet trajectory closed proximately to the solid surfaces $\left(H=80 \mathrm{~mm}, \alpha=10^{\circ}\right)$.

( $z$-direction) after it comes into collision with the stationary plate. This swirling flow boundary layer around the disk may obstruct the impinging jet flow to penetrate the minimum gap between the rotating disk and the stationary plate. The flow feature in the vicinity of the interfacial contact zone between the rotating disk and the stationary plate (here the interfacial contact means that the rotating disk is not in real contact with the stationary plate) is consistent with the experimental measurement presented by O'Donovan et al. [19].

Figure 4 presents the computed impinging jet trajectory closed proximately to the solid surfaces, which reflects the influence of the rotating disk on the impinging jet flow. Specifically, the jet nozzle outlets for different cases are all fixed at $H=80 \mathrm{~mm}$ with oblique angle of $10^{\circ}$. For the free oblique jet impingement, as seen in Figure 4(a), a stronger wall jet is formed in the negative $x$-direction after the free jet impinges on the target plate, and the wall jet diffuses in the traverse direction gradually over the plate. When the disk is suspended above the plate and remains stationary, it acts as a bluff body to the impinging jet flow. Because the gap between the disk and the surface is extremely small, little of the impinging jet is allowed to pass through this minimum 

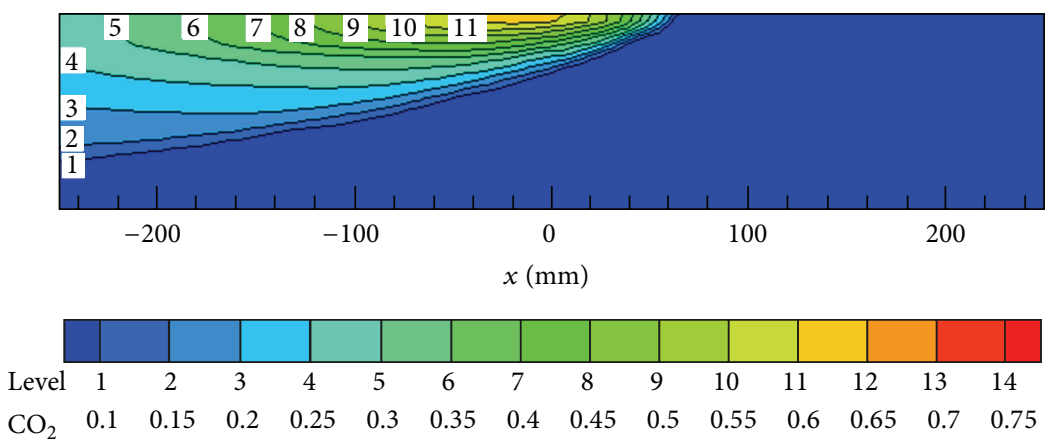

(a) Free oblique jet, $V_{j}=30 \mathrm{~m} / \mathrm{s}$

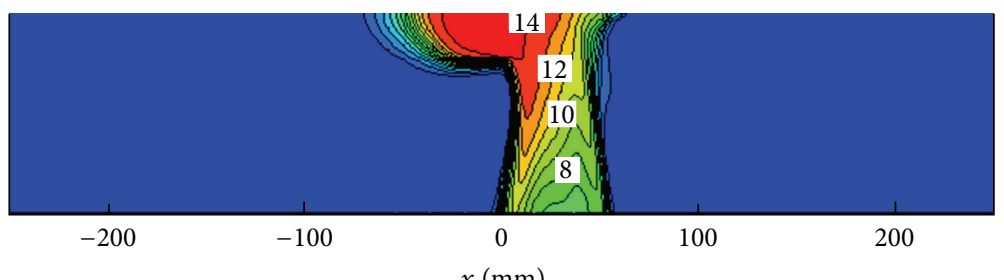

$x(\mathrm{~mm})$

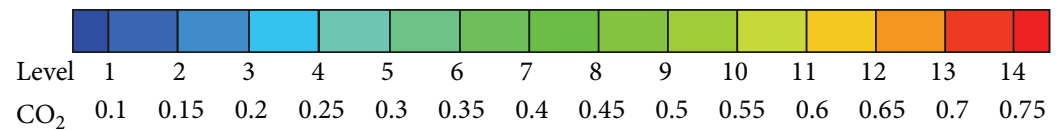

(b) $\Omega=0 \mathrm{rpm}, V_{j}=30 \mathrm{~m} / \mathrm{s}$
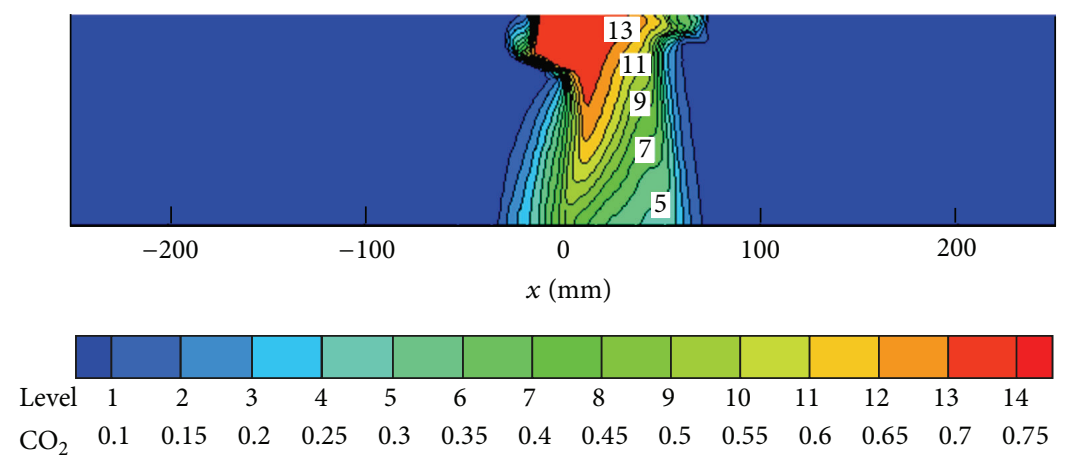

(c) $\Omega=2000 \mathrm{rpm}, V_{j}=30 \mathrm{~m} / \mathrm{s}$
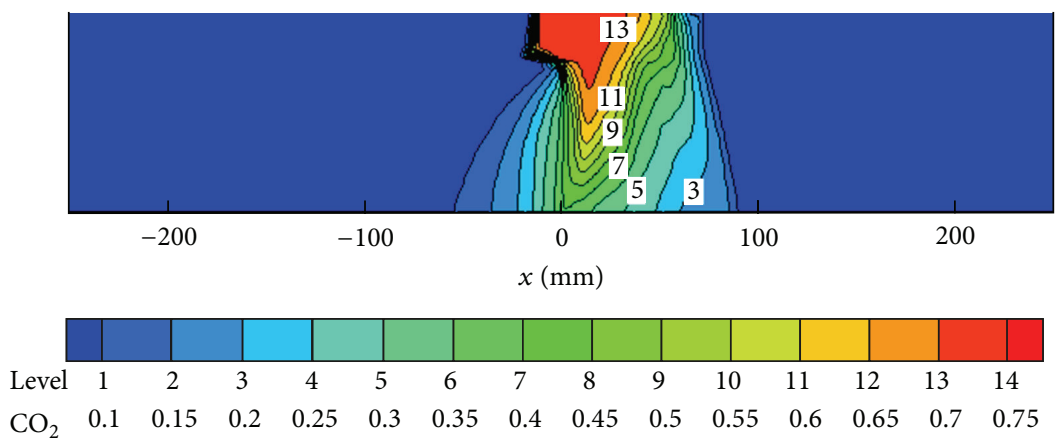

(d) $\Omega=4000 \mathrm{rpm}, V_{j}=30 \mathrm{~m} / \mathrm{s}$

FIGURE 5: Contours of $\mathrm{CO}_{2}$ mass fraction near the plate surface $\left(H=80 \mathrm{~mm}, \alpha=10^{\circ}\right)$. 


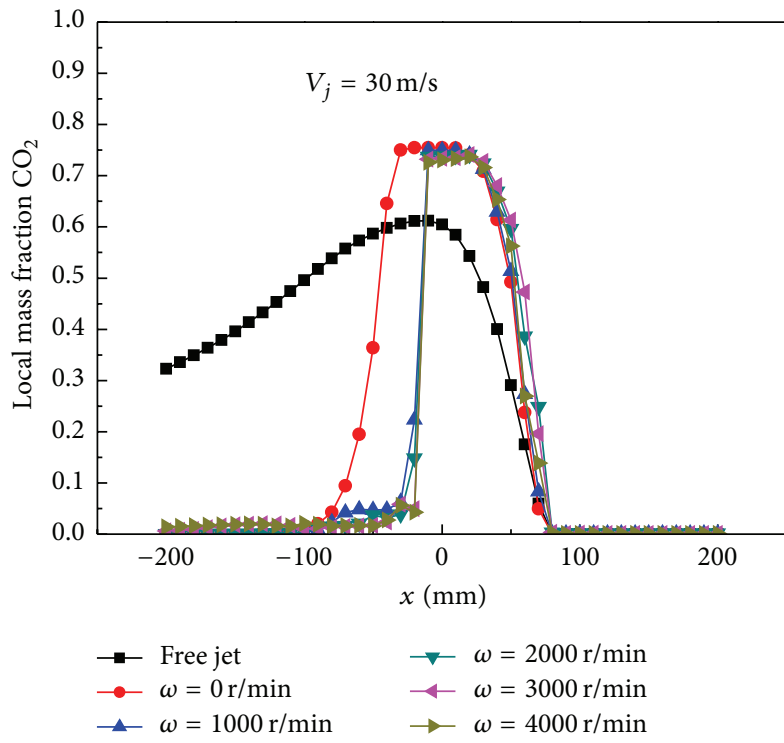

(a) Centre-line in $x o y$ section

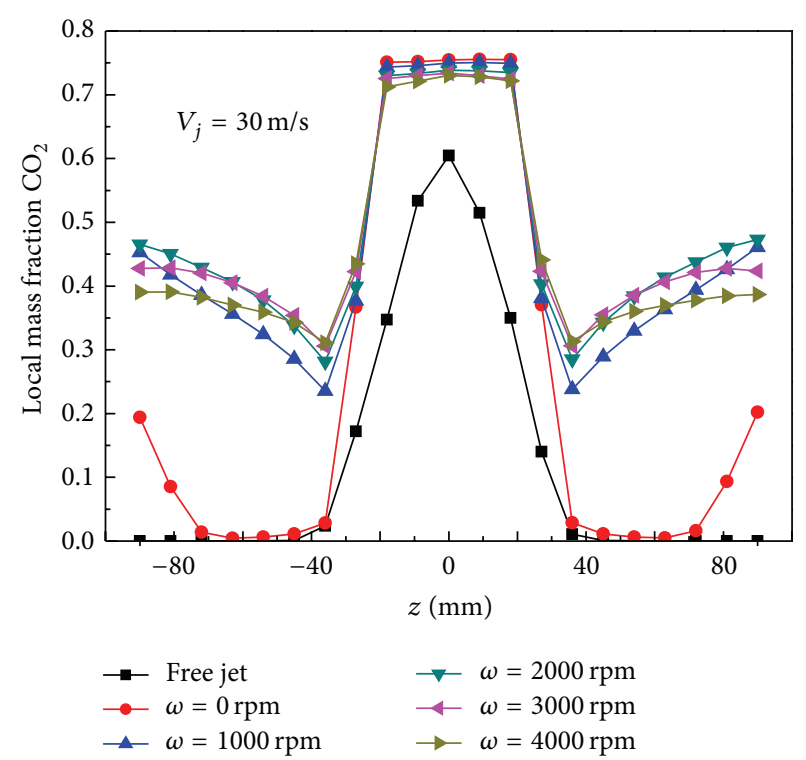

(b) Centre-line in $y \mathrm{o} z$ section

Figure 6: Effect of disk rotational speed on local mass fraction of $\mathrm{CO}_{2}$ near the plate surface $\left(\mathrm{H}=80 \mathrm{~mm}, \alpha=10^{\circ}\right)$.

gap. And the impinging jet passing through the minimum gap has very weak flow momentum to form the wall jet along the negative $x$-direction due to tremendous flow loss inside the narrow gap channel. Vast amount of the impinging jet is forced to form wall jets in the traverse directions, as seen in Figure 4(b). Once the disk rotates clockwise, the coupling effect with the swirl flow induced by the rotating disk enhances the jet impinging capacity in the wedge zone between the rotating disk and the stationary plate, as seen in Figure 4(c). The impinging jet passing through the minimum gap is entrained by the disk flows in the same direction as the rotating disk until it comes into detachment with the surface. As would be expected, the wall jet across the rotating disk is forced to flow along transverse directions with stronger diffuse capacity. As the disk rotational speed increases, the effect of the rotating disk on the impinging jet flow behaves more significantly, as seen in Figure 4(d). In this case, the tangential velocity of swirl flow near the rotating disk rim is greater than the impinging jet velocity. The impinging jet passing through the minimum gap is accelerated by the disk flows, even being transported into the impinging jet zone again. Insight regarding the effect of rotating disk on the impinging jet flow with different jet velocities is displayed in Figures 4(c), 4(e), and 4(f). The impinging jet with small inject velocity is difficult to penetrate through the minimum gap to follow by the disk flows. On the other hand, the wall jets forced to flow along transverse directions are easy to induce toward the negative $x$-direction under the disk flows.

Figure 5 presents the computed contours of $\mathrm{CO}_{2}$ mass fraction near the plate surface. Specifically, the jet nozzle outlets for different cases are all fixed at $H=80 \mathrm{~mm}$ with oblique angle of $10^{\circ}$. For the free oblique jet impingement, as seen in Figure 5(a), the surrounding ambient fluid is suctioned toward the wall by the pumping action of impinging jet, diluting the local mass fraction of $\mathrm{CO}_{2}$ in the stagnation zone, while, for the case where the disk is suspended above the plate and remains stationary, little of the impinging jet is pressed into the gap zone without being entrained by the disk flows. Therefore, the local mass fraction of $\mathrm{CO}_{2}$ in the stagnation zone takes on the maximum in the discussed cases. And the penetration of the wall jet along the negative $x$ direction seems stronger than that when the disk is rotated, as seen in Figure 5(b). When the disk is rotated clockwise, the rotational effect of disk tends to lift the streamline of the wall jet off the plate surface on the rear of the disk. Besides, the jet passing through the minimum gap between the rotating disk and the stationary plate must penetrate the boundary layer flow around the rotating disk. Thus, the local mass fraction of $\mathrm{CO}_{2}$ in the stagnation zone decreases a little in comparison with the stationary disk case. However the diffusion rate and coverage region of the wall jet along transverse direction are both bigger than those when the disk is stationary, as seen in Figure 5(c). This is contributed to the swirl flow effect. As the disk rotational speed increases, the impinging jet should overcome stronger boundary layer flow around the rotating disk to penetrate into the interfacial contact zone between the rotating disk and the stationary plate. The wall jet passing around the rotating disk is diffused rapidly and widely under the stronger disk flows, as seen in Figure 5(d).

In Figures 6-9, the effects of disk rotational speed, impinging jet velocity, impinging distance, and jet oblique angle on local mass fraction of $\mathrm{CO}_{2}$ at centre-lines near the plate surface are presented, respectively. It has been addressed in Figure 5 that the rotating disk has a significant effect on the local mass fraction of $\mathrm{CO}_{2}$ near the plate surface, decreasing the local mass fraction of $\mathrm{CO}_{2}$ in the stagnation zone a little in comparison with the stationary disk case. From Figure 6, it is seen that the disk rotational speed ranging 


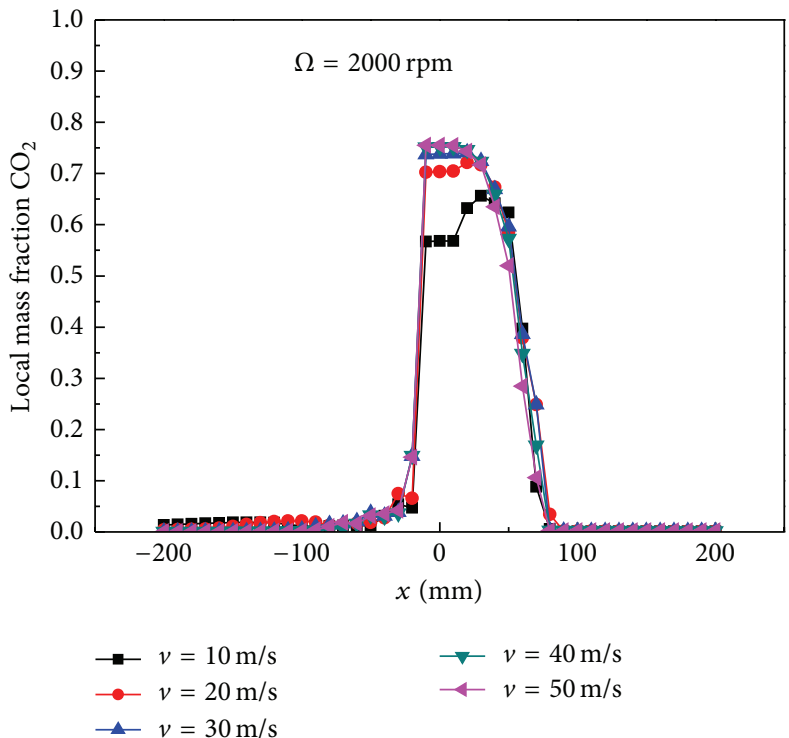

(a) Centre-line in $x$ o $y$ section

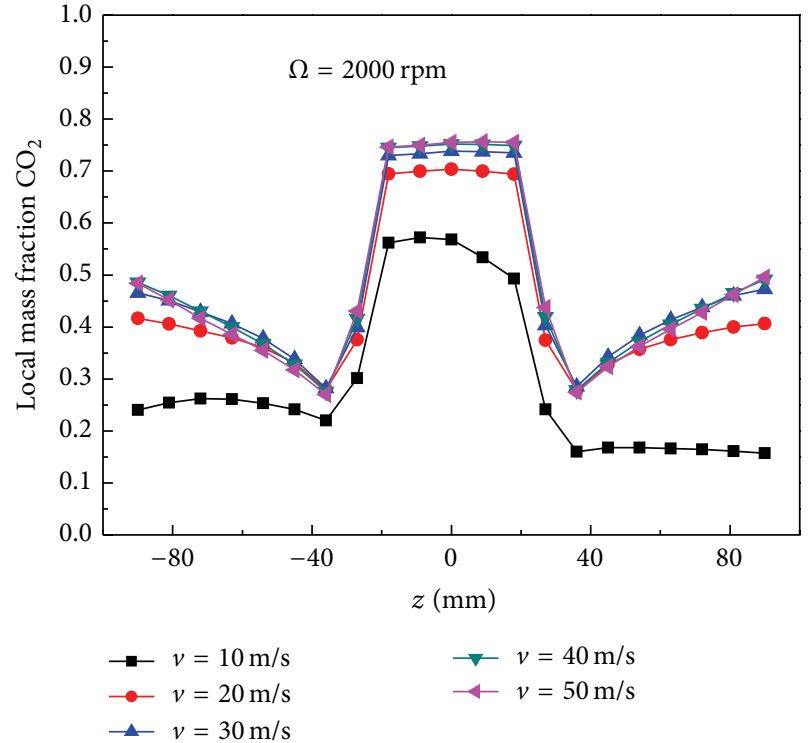

(b) Centre-line in $y o z$ section

FIGURE 7: Effect of impinging jet velocity on local mass fraction of $\mathrm{CO}_{2}$ near the plate surface $\left(H=80 \mathrm{~mm}, \alpha=10^{\circ}\right)$.

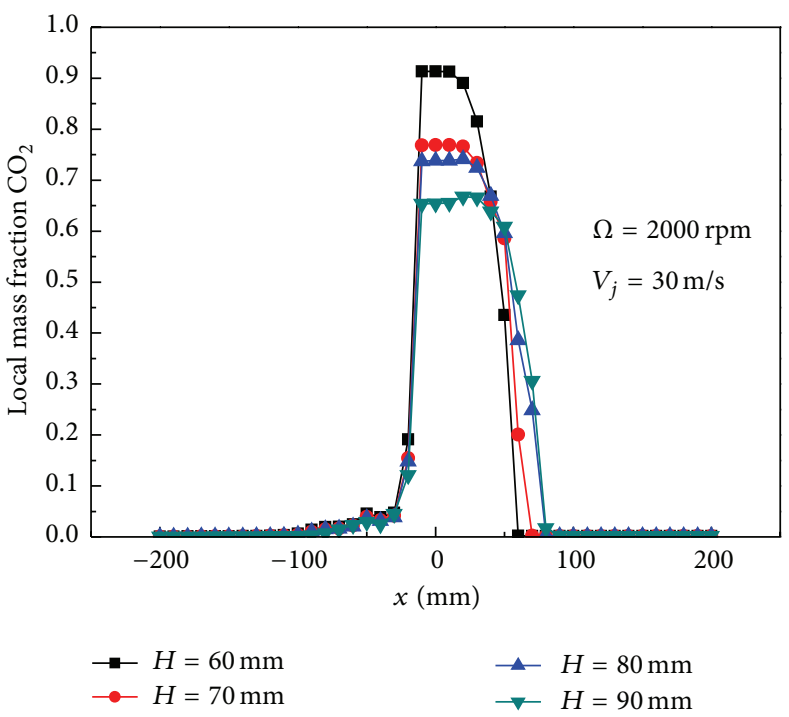

(a) Centre-line in $x$ oy section

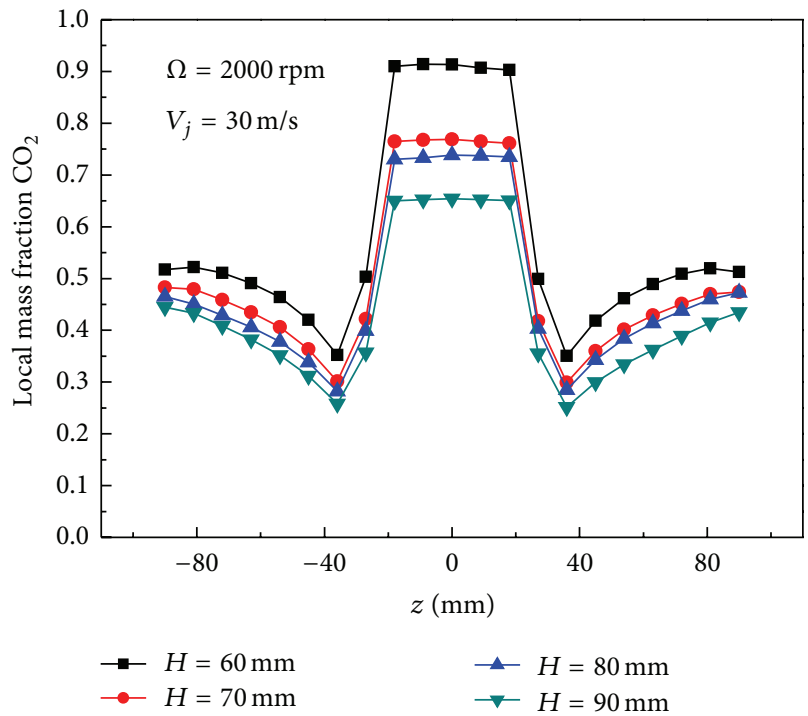

(b) Centre-line in $y \mathrm{o} z$ section

FIGURE 8: Effect of impinging distance on local mass fraction of $\mathrm{CO}_{2}$ near the plate surface $\left(\alpha=10^{\circ}\right)$.

between $1000 \mathrm{rpm}$ and $4000 \mathrm{rpm}$ seems to have relatively weaker effects on the distribution of local mass fraction of $\mathrm{CO}_{2}$ under impinging jet velocity of $30 \mathrm{~m} / \mathrm{s}$. With the increase of impinging jet velocity, the ingress capacity of jet into the beneath of the rotating disk is enhanced. Therefore, the local mass fraction of $\mathrm{CO}_{2}$ at the interfacial contact zone is increased with the increase of impinging jet velocity, as seen in Figure 7. For the disk rotational speed of $2000 \mathrm{rpm}$, when the impinging jet velocity is increased from $10 \mathrm{~m} / \mathrm{s}$ to $20 \mathrm{~m} / \mathrm{s}$ (nearly the tangential velocity of swirl flow near the rotating disk rim), the ingress capacity of jet into the beneath of the rotating disk is enhanced obviously. Once the impinging jet velocity reaches up to $30 \mathrm{~m} / \mathrm{s}$, the impinging jet velocity is substantially greater than the tangential velocity of the rotating disk rim, prompting its penetration capacity to the boundary layer flow around the disk; therefore the local mass fraction of $\mathrm{CO}_{2}$ at the interfacial contact zone is increased gradually. With regard to the jet nozzle orientation, the impinging distance has an important effect on the jet ingress capacity into the interfacial contact zone. With the decrease of the impinging distance, the jet ingress capacity into the interfacial contact zone is enhanced significantly, as seen in 


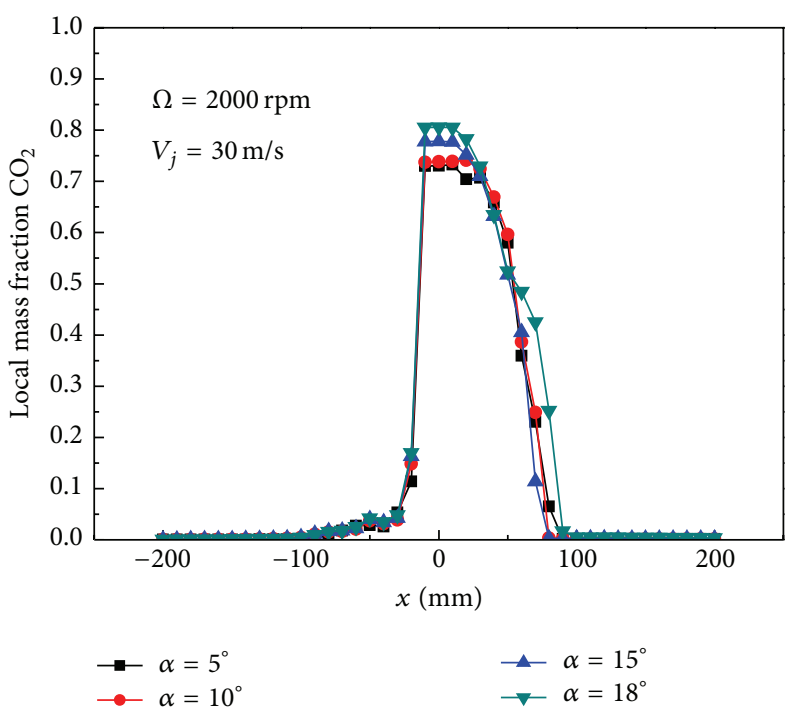

(a) Centre-line in $x o y$ section

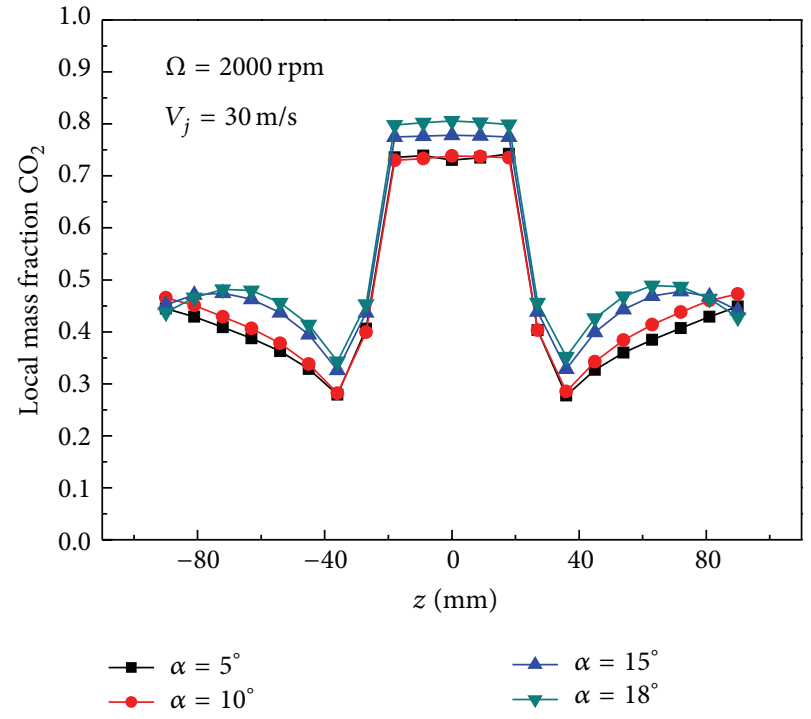

(b) Centre-line in $y_{\mathrm{o}} z$ section

FIGURE 9: Effect of jet oblique angle on local mass fraction of $\mathrm{CO}_{2}$ near the plate surface $(\mathrm{H}=80 \mathrm{~mm})$.

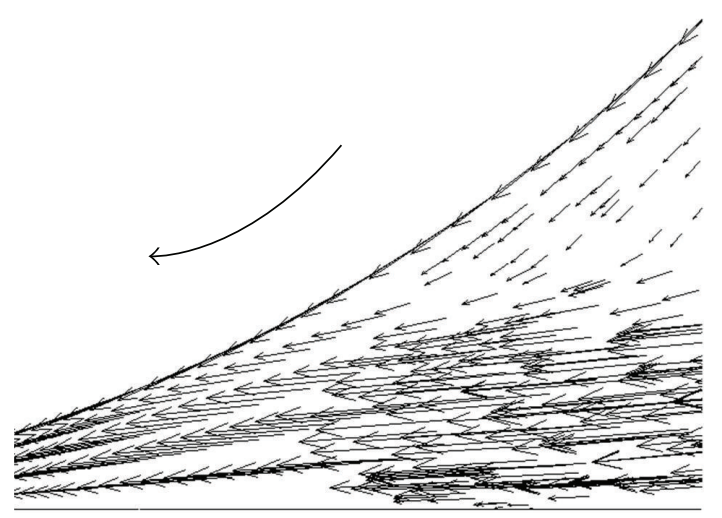

(a) $\alpha=5^{\circ}$

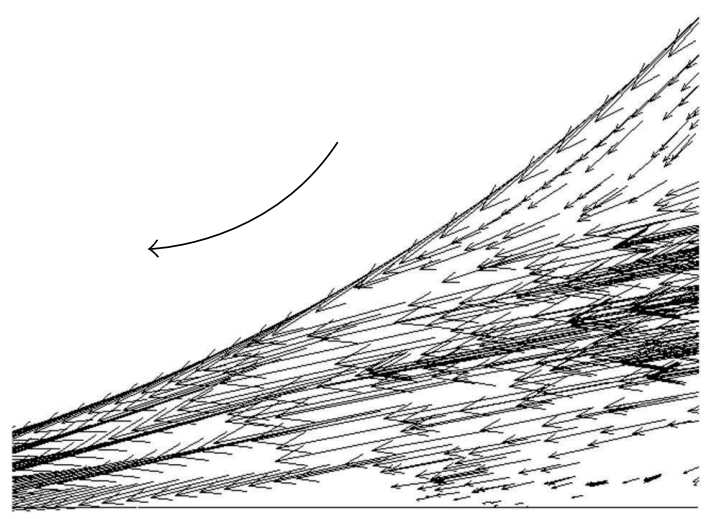

(b) $\alpha=10^{\circ}$

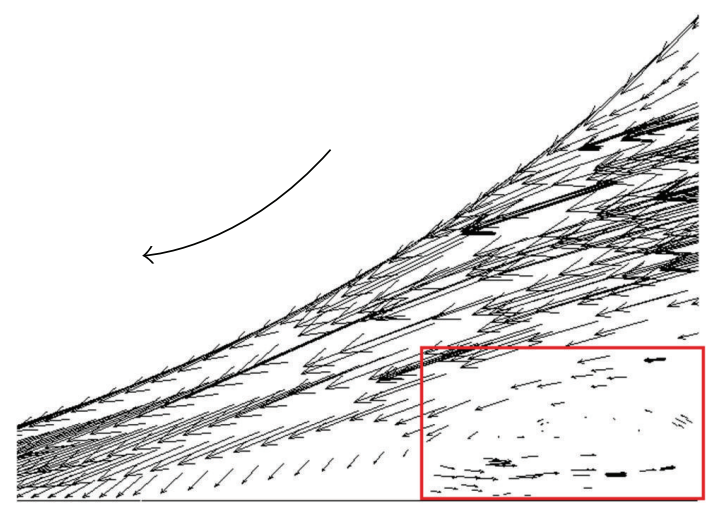

(c) $\alpha=15^{\circ}$

FIgURE 10: Local velocity vectors in the wedge zone $\left(\Omega=2000 \mathrm{rpm}, V_{j}=30 \mathrm{~m} / \mathrm{s}\right.$, and $\left.H=80 \mathrm{~mm}\right)$. 


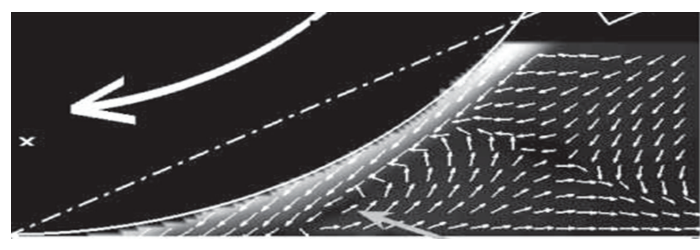

FIGURE 11: Flow fields in vicinity of a rotating grinding wheel [19].

Figure 8. While, for the jet oblique angle, it is seen from Figure 9 that the maximum local mass fraction of $\mathrm{CO}_{2}$ at the interfacial contact zone is achieved at the largest jet oblique angle in the presented cases. It is suggested that a large oblique angle of the jet nozzle is preferred as possible as it could be used in the real application, ensuring that the impinging jet could be directly introduced to the interfacial contact zone.

Figure 10 presents the computed local velocity vectors in the wedge zone between the rotating disk and the stationary plate, which is displayed for the rotational speed of $2000 \mathrm{rpm}$ and jet velocity of $30 \mathrm{~m} / \mathrm{s}$. Specifically, the jet nozzle outlet is fixed at $H=80 \mathrm{~mm}$ with different oblique angles. For oblique angle which is less than $10^{\circ}$, the impinging jet is nearly parallel to the heated wall; no flow recirculation zone occurs away from the interfacial contact zone in the positive $x$-direction. When the oblique angle is increased to $15^{\circ}$, weak flow recirculation is observed. This flow feature in the vicinity of a rotating disk is consistent with the experimental measurement presented by O'Donovan et al. [19], as shown in Figure 11.

\section{Conclusions}

This paper summarizes a numerical investigation of the swirl flow effect on jet impingement behaviors simulating the grinding process. Under the present research cases, the results are summarized as follows.

(1) The rotating disk suspended above the surface adds more complexity to the flow field of jet impingement on a stationary plate. The swirl flow induced by the rotating disk rim comes into close proximity to the plate surface in the same direction as the rotating disk, coupled with the impinging jet flow in the front wedge between the rotating disk and the stationary plate surface. This swirling flow around the rotating disk obstructs the impinging jet flow to penetrate into the interfacial contact zone and forces the wall jet across the rotating disk to flow along transverse directions.

(2) For the given jet impinging velocity and nozzle orientation, as the disk rotational speed increases, the effect of the rotating disk on the impinging jet flow behaves more significantly. The impinging jet with small inject velocity is difficult to penetrate through the minimum gap to follow by the disk swirl flows. For smaller jet impinging distance or larger oblique angle, the flow recirculation away from the interfacial contact zone becomes stronger.

\section{Conflict of Interests}

The authors declare that there is no conflict of interests regarding the publication of this paper.

\section{Acknowledgment}

The authors gratefully acknowledge the financial support for this project from the National Natural Science Foundation of China (Grant no. 51076063).

\section{References}

[1] S. Malkin and C. Guo, "Thermal analysis of grinding," CIRP Annals-Manufacturing Technology, vol. 56, no. 2, pp. 760-782, 2007.

[2] K. Ramesh, H. Huang, and L. Yin, "Analytical and experimental investigation of coolant velocity in high speed grinding," International Journal of Machine Tools and Manufacture, vol. 44, no. 10, pp. 1069-1076, 2004.

[3] H. Z. Choi, S. W. Lee, and H. D. Jeong, "A comparison of the cooling effects of compressed cold air and coolant for cylindrical grinding with a CBN wheel," Journal of Materials Processing Technology, vol. 111, no. 1-3, pp. 265-268, 2001.

[4] T. Nguyen and L. C. Zhang, "An assessment of the applicability of cold air and oil mist in surface grinding," Journal of Materials Processing Technology, vol. 140, no. 1-3, pp. 224-230, 2003.

[5] H. Martin, "Heat and mass transfer between impinging gas jets and solid surfaces," Advances in Heat Transfer, vol. 13, pp. 1-60, 1977.

[6] K. Jambunathan, E. Lai, M. A. Moss, and B. L. Button, "A review of heat transfer data for single circular jet impingement," International Journal of Heat and Fluid Flow, vol. 13, no. 2, pp. 106-115, 1992.

[7] B. Weigand and S. Spring, "Multiple jet impingement-a review," Heat Transfer Research, vol. 42, no. 2, pp. 101-142, 2011.

[8] D. Babic, D. B. Murray, and A. A. Torrance, "Mist jet cooling of grinding processes," International Journal of Machine Tools and Manufacture, vol. 45, no. 10, pp. 1171-1177, 2005.

[9] T. Wang, J. L. Gaddis, and X. Li, "Mist/steam heat transfer of multiple rows of impinging jets," International Journal of Heat and Mass Transfer, vol. 48, no. 25-26, pp. 5179-5191, 2005.

[10] M. F. Koseoglu and S. Baskaya, "The role of jet inlet geometry in impinging jet heat transfer, modeling and experiments," International Journal of Thermal Sciences, vol. 49, no. 8, pp. 14171426, 2010.

[11] M. A. Pakhomov and V. I. Terekhov, "Enhancement of an impingement heat transfer between turbulent mist jet and flat surface," International Journal of Heat and Mass Transfer, vol. 53, no. 15-16, pp. 3156-3165, 2010.

[12] H. Shokouhmand and M. M. Heyhat, "A numerical study on heat transfer enhancement in a mist/air impingement jet," Journal of Enhanced Heat Transfer, vol. 17, no. 3, pp. 231-242, 2010.

[13] X. M. Tan, J. Z. Zhang, B. Liu et al., "Experimental investigation on heat transfer enhancement of mist/air impingement jet," Science China Technological Sciences, vol. 56, pp. 2456-2464, 2013.

[14] Y. Z. Yu, J. Z. Zhang, and H. S. Xu, "Convective heat transfer by a row of confined air jets from round holes equipped with 
triangular tabs," International Journal of Heat and Mass Transfer, vol. 72, pp. 222-233, 2014.

[15] N. Saniei and X. Yan, "Experimental study of heat transfer from a disk rotating in an infinite environment including heat transfer enhancement by jet impingement cooling," Journal of Enhanced Heat Transfer, vol. 7, no. 4, pp. 231-245, 2000.

[16] Y. Minagawa and S. Obi, "Development of turbulent impinging jet on a rotating disk," International Journal of Heat and Fluid Flow, vol. 25, no. 5, pp. 759-766, 2004.

[17] A. Abdel-Fattah, "Numerical simulation of turbulent impinging jet on a rotating disk," International Journal for Numerical Methods in Fluids, vol. 53, no. 11, pp. 1673-1688, 2007.

[18] T. Astarita and G. Cardone, "Convective heat transfer on a rotating disk with a centred impinging round jet," International Journal of Heat and Mass Transfer, vol. 51, no. 7-8, pp. 1562-1572, 2008.

[19] T. S. O'Donovan, D. B. Murray, and A. A. Torrance, "Jet heat transfer in the vicinity of a rotating grinding wheel," Proceedings of the Institution of Mechanical Engineers, Part C: Journal of Mechanical Engineering Science, vol. 220, no. 6, pp. 837-845, 2006.

[20] J. Zhang, X. Tan, B. Liu, and X. Zhu, "Investigation for convective heat transfer on grinding work-piece surface subjected to an impinging jet," Applied Thermal Engineering, vol. 51, no. 1-2, pp. 653-661, 2013.

[21] S. Ebbrell, N. H. Woolley, Y. D. Tridimas, D. R. Allanson, and W. B. Rowe, "Effects of cutting fluid application methods on the grinding process," International Journal of Machine Tools and Manufacture, vol. 40, no. 2, pp. 209-223, 2000.

[22] N. Zuckerman and N. Lior, "Impingement heat transfer: correlations and numerical modeling," Journal of Heat Transfer, vol. 127, no. 5, pp. 544-552, 2005.

[23] J. Zhu and T.-H. Shih, "Computation of confined coflow jets with three turbulence models," International Journal for Numerical Methods in Fluids, vol. 19, no. 10, pp. 939-956, 1994.

[24] M. A. R. Sharif and K. K. Mothe, "Evaluation of turbulence models in the prediction of heat transfer due to slot jet impingement on plane and concave surfaces," Numerical Heat Transfer B: Fundamentals, vol. 55, no. 4, pp. 273-294, 2009.

[25] X. Zhu, J. Zhang, and X. Tan, "Numerical simulation on heat transfer inside rotating porous disk subjected to local heat flux," Science China Technological Sciences, vol. 56, no. 7, pp. 16571666, 2013.

[26] J. Z. Zhang, X. M. Tan, and X. D. Zhu, "Investigation on convective heat transfer over a rotating disk with discrete pins," Heat and Mass Transfer, vol. 50, no. 1, pp. 85-94, 2014. 


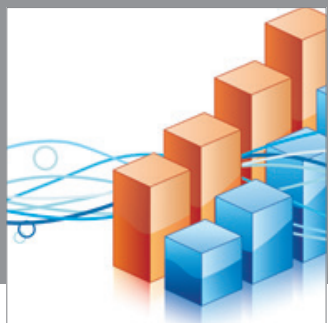

Advances in

Operations Research

mansans

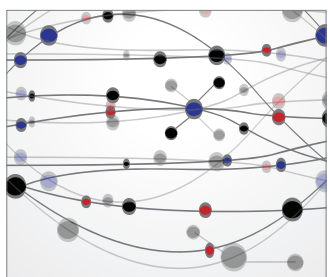

The Scientific World Journal
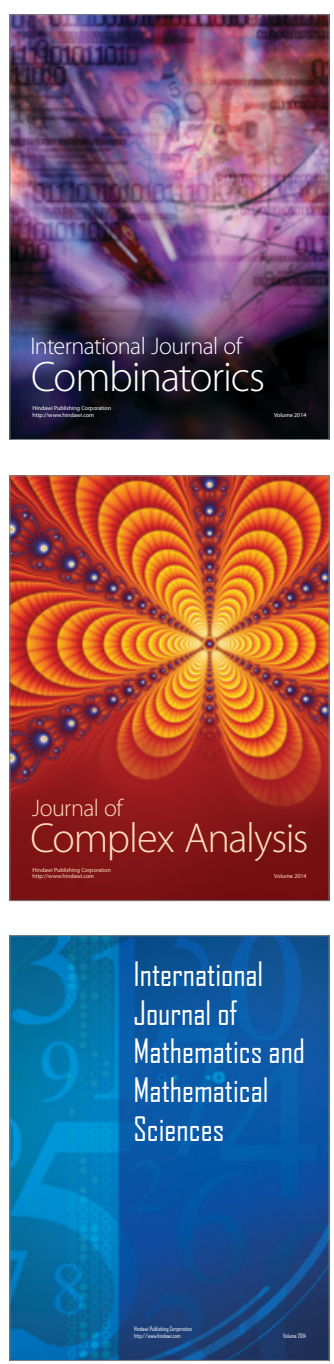
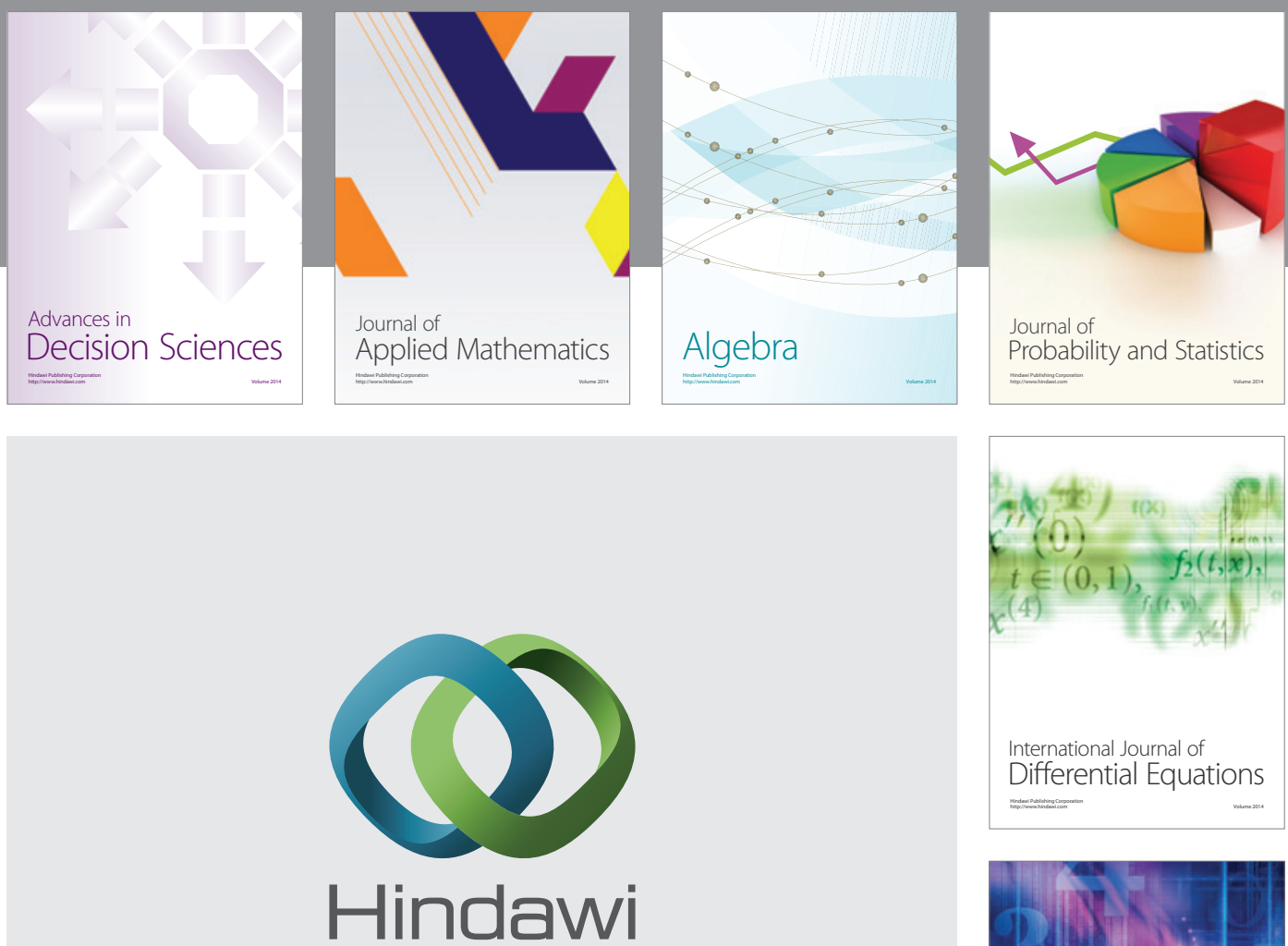

Submit your manuscripts at http://www.hindawi.com
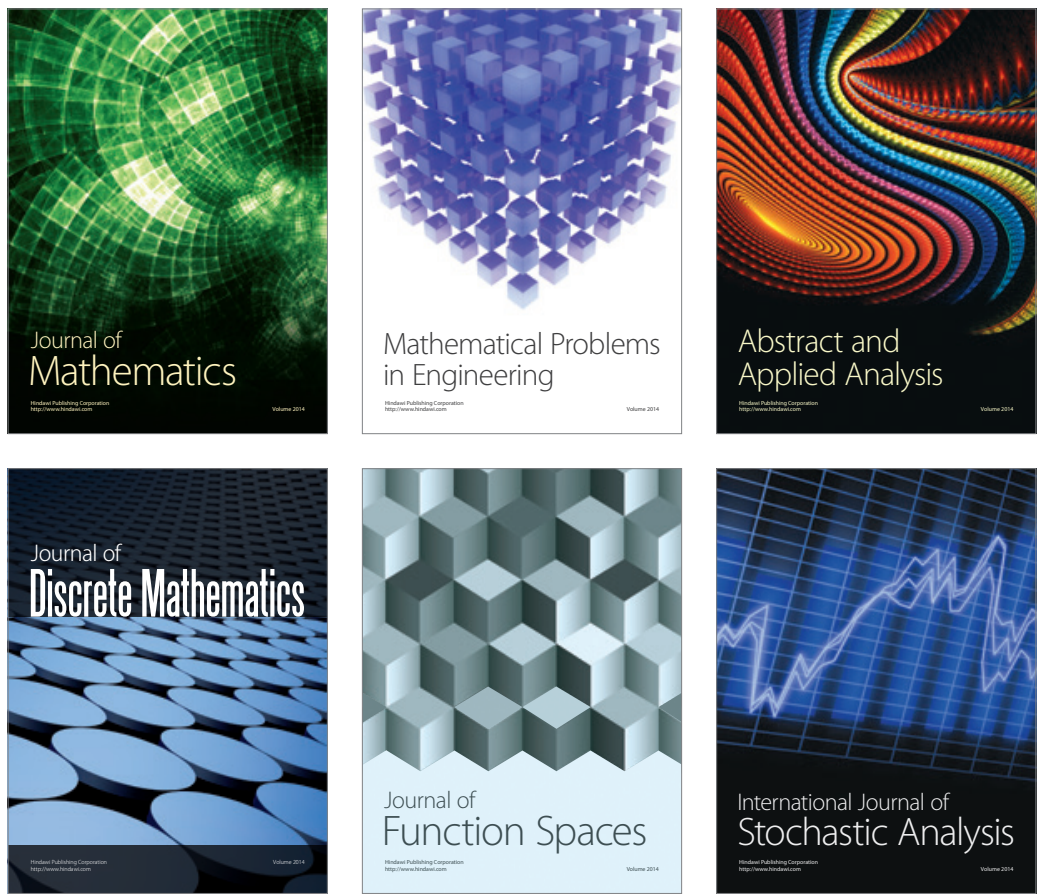

Journal of

Function Spaces

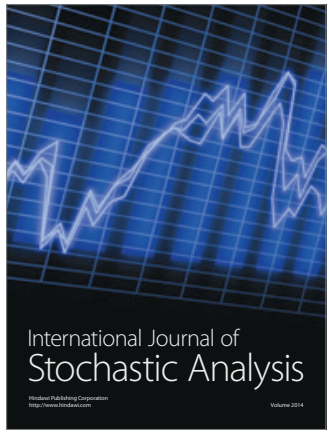

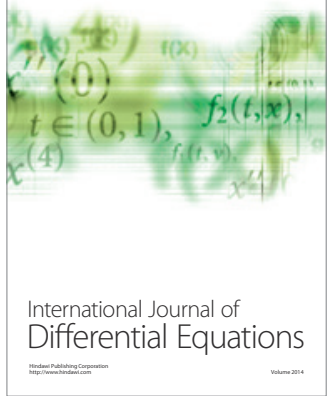
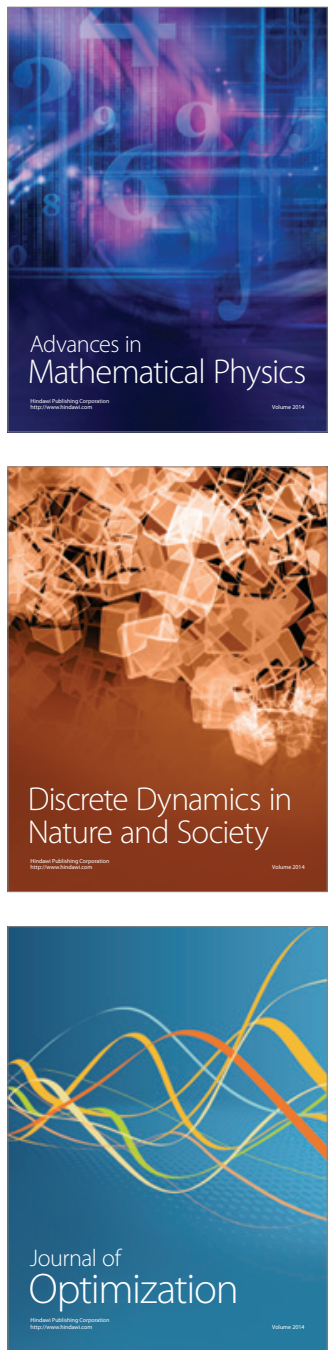